\title{
A poesia em prosa de Charles Baudelaire e Fernando Pessoa: cruzamentos
}

\author{
Luciana Paiva Coronel*
}

\begin{abstract}
Resumo: A prosa poética do Livro do desassossego, de Fernando Pessoa constitui obra privilegiada para o estudo das contradições da modernidade estética neste autor. Fragmentária e desalinhavada, esta forma literária apresenta uma afinidade inequívoca com os Pequenos poemas em prosa de Charles Baudelaire, o iniciador da lírica moderna. Em que pesem as semelhanças, visíveis nitidamente no plano formal, há inúmeras dessemelhanças entre a visão de mundo do poeta português e a visão de mundo do poeta francês no que diz respeito ao julgamento que cada um faz acerca das peculiaridades da vida moderna. Realizar um cruzamento entre estas distintas visões de mundo, enraizadas em formas poéticas bastante próximas, é o que se pretende neste trabalho.
\end{abstract}

Palavras-chave: Poesia moderna; poemas em prosa; prosa poética

\begin{abstract}
Prose poetry in the Livro do desassossego by Portuguese author Fernando Pessoa is a key feature for the study of the contradictions of modern aesthetics in the work of this author. This fragmented work by Pessoa reveals strong affinity with Spleen de Paris, by French author Charles Baudelaire, the founder of modern poetry. Despite the great many formal similarities between both authors' poetical writing, there are also several differences between their world views when it comes to the way each author addresses the peculiarities of modern life. This study aims at contrasting these world views, which take root from very close poetic forms.
\end{abstract}

Keywords: modern poetry; prose poems; prose poetry.

Se Charles Baudelaire pode ser considerado o primeiro lírico moderno, autor da primeira poesia na qual a cidade torna-se o tema central de uma elaboração poética que se conforma a partir de temas eminentemente urbanos, como a multidão e as avenidas, na obra de Fernando Pessoa traços modernos e antimodernos convivem lado a lado, iluminando muitas das ambigüidades da vida moderna que Fernando Pessoa pretendeu recriar em sua poesia.

Não bastasse a própria criação da heteronomia, por si só representativa da máxima moderna "J'ai un autre", de Rimbaud, Pessoa vai apresentar nos poemas em prosa do Livro de desassossego um experimentalismo similar ao que demonstram os Pequenos poemas em prosa de Baudelaire. Em ambos os casos, não se trata apenas de inovação formal, mas também desolação, obscuridade, alienação e desintegração.

\footnotetext{
* Luciana Paiva Coronel é Graduada em História pela UFRGS, Mestre em Literatura Brasileira pela UFRGS e doutor na mesma área pela USP. Atualmente é professora no Centro Universitário Metodista IPA
} 
Conforme Malcolm Bradbury e James McFarlane expuseram em seu Modernismo Guia geral (1999, p.22), a definição de modernismo passa pela noção de um "encrespamento da dura superfície naturalista por um estado de multiplicidade da consciência", resposta da imaginação a um mundo progressivamente secularizado e urbanizado.

O Livro do desassossego e os Pequenos poemas em prosa identificam-se exatamente com esta reação ao positivismo/naturalismo por meio de uma forma multifacetada e indefinível. Se "o Modernismo é consciência da desordem, do desespero e da anarquia" (BRADBURY, MCFARLANE, p.31), os poemas em prosa de Pessoa e de Baudelaire aproximam-se inequivocamente ao espírito do modernismo. Desmanchando a superfície dada do real, lançam-se como estilhaços de sentido em formas inusitadas, um romance sem fio narrativo, sem uma noção determinada de tempo e sem fatos propriamente ditos no caso do autor português, e uma poesia sem ritmo e sem rima, solta e adaptada aos movimentos líricos da alma um habitante da grande cidade, no caso do poeta francês.

“Autobiografia sem fatos”, um dos subtítulos paradoxais do livro de Pessoa, traduz a natureza desalinhavada e caleidoscópica da obra, composta de insights destacáveis oriundos da mente inquieta do semi-heterônimo Bernardo Soares, narrador principal, mas não exclusivo do Livro do desassossego. Forma “sem pé nem cabeça”, a auto-definição do primeiro lírico moderno acerca de sua obra revela igualmente a consciência do autor acerca dos traços insólitos e inovadores de seus poemas narrativos.

Romance, anti-romance, diário-íntimo, livro, livro em potência, livro-sonho, livrodesespero, livro em ruína, antilivro, eis algumas designações apontadas pela crítica na difícil tarefa de conceituar o livro-caos do desassossego de Fernando Pessoa. Fragmentos descontínuos de tortuosa fantasia, Os pequenos poemas em prosa são também inomináveis, fragmentos vibrantes, passíveis de ser emendados conforme a vontade do leitor, ao qual são oferecidos como última possibilidade da poesia na civilização comercializada e dominada pela técnica.

A feição próxima do caos de ambas as obras autoriza sua consideração como modernas, de acordo com a síntese criada por Marshall Berman - "tudo que é sólido se desmancha no ar", fragmento extraído do Manifesto Comunista, de Karl Marx capaz de definir a essência da vida moderna:

Todos são movidos pelo desejo de mudança - de autotransformação e de transformação do mundo em redor - e pelo terror da desorientação e da desintegração, o terror da vida que se desfaz em pedaços. (BERMAN, 1986, p.13). 
Se, por um lado, a feição provisória, indefinida e em interminável transição permite a consideração do Livro do desassossego e dos Pequenos poemas em prosa como obras de teor inequivocamente moderno, por outro lado o traço da vocação para a evasão da realidade da obra de Pessoa e a "aristocracia da individualidade" cultivada por Bernardo Soares, principal narrador do primeiro, constituem traços eminentemente antimodernos.

Já no Prefácio, Fernando Pessoa apresenta Soares como alguém que nunca passara por nenhum agrupamento, que "não pertencera nunca a uma multidão" (PESSOA, 1999, p.40). Teresa Cruz, no posfácio da obra $O$ pintor da vida moderna, de Charles Baudelaire, identifica exatamente o enfrentamento corajoso da multidão como o primeiro sintoma efetivamente moderno da sensibilidade de Baudelaire:

O pintor da vida moderna é, antes de mais, um ser urbano, 'grande amante da multidão e do incógnito', que 'mergulha na multidão como num imenso reservatório de eletricidade', como 'um espelho tão imenso quanto esta multidão; como um caleidoscópio dotado de consciência. (BAUDELAIRE, 1993, p.79).

Moderna é a atitude se defrontar-se com a multidão, o que não exclui o susto e o temor da perda da individualidade, mas inclui o fascínio do novo, o heroísmo de aceitar a ameaça de dissolução do eu como nova condição do artista, a quem cabe representar as grandes multidões anônimas das cidades como um dos aspectos mais marcantes da vida social do período compreendido entre meados do século XIX e o início do século XX.

Charles Baudelaire, nos poemas em prosa do Spleen de Paris, dá sinais de uma sensibilidade notadamente moderna em relação às grandes aglomerações humanas da cidade, como se pode perceber no fragmento número 12, intitulado exatamente "As multidões":

Não é dado a qualquer um penetrar na multidão: tal desfrute é uma arte, e só faz, às expensas do gênero humano, esse lauto banquete de vitalidade quem desde o berço recebeu de uma fada o gosto do disfarce e da máscara, o ódio do domicílio e a paixão da viagem.

Multidão, solidão: termos iguais e conversíveis para o poeta ativo e fecundo. Quem não sabe povoar a própria solidão também não sabe estar só entre a gente atarefada.

O poeta goza desse incomparável privilégio de poder, quando lhe agrada, ser ele mesmo e um outro. Como essas almas errantes que buscam um corpo, ele entra, se quiser, na personagem de alguém.. (BAUDELAIRE, 1995, p.41).

Fernando Pessoa, por meio da voz de Bernardo Soares, plácido escrevente do livro de contabilidade, representa uma atitude bastante diversa diante dos desafios da vida moderna, como se pode ler já no fragmento 1 do Livro do desassossego:

Nasci em um tempo em que a maioria dos jovens haviam perdido a crença em Deus, pela mesma razão que os seus maiores a haviam tido - sem saber porquê. E então, porque o espírito humano tende naturalmente para criticar porque sente, e não se pensa, a maioria desses jovens escolheu a Humanidade como sucedâneo de Deus. Pertenço, porém, àquela espécie de homens que estão sempre na margem daquilo a que pertencem, nem vêem só a multidão de que são, como também os grandes espaços que há ao lado. Por isso, nem abandonei Deus tão amplamente como eles, nem aceitei nunca a Humanidade.[...] Este culto da Humanidade, com seus ritos de Liberdade e Igualdade, pareceu-me sempre uma revivescência dos cultos antigos, 
em que animais eram como deuses, ou deuses tinham cabeça de animais. (PESSOA, 1999, p.45).

O narrador mostra-se tão disposto a enxergar a multidão, de que é parte, como "os grandes espaços" que o isolam dentro da mesma, ratificando a sua singular individualidade. $\mathrm{Na}$ contracorrente dos ideais modernos apresentados pela Revolução Francesa, Soares se apresenta muito cético em relação à Humanidade em que os jovens de seu tempo depositam grandes esperanças, não lhe restando mais que o recuo na própria subjetividade como reduto primordial da existência:

Assim, não sabendo crer em Deus, e não podendo crer numa soma de animais, fiquei, como outros, na orla das gentes [...].

A quem, como eu, assim, vivendo não sabe ter vida, que resta senão como a meus poucos pares, a renúncia por modo e a contemplação por destino? Não sabendo o que é a vida religiosa, nem podendo sabê-lo, porque se não tem fé com a razão; não podendo ter fé na abstração do homem, nem sabendo mesmo que fazer dela perante nós, ficava-nos, como motivo de ter alma, a contemplação estética da vida. E assim, alheios à solenidade de todos os mundos, indiferentes ao divino e desprezadores do humano, entregamo-nos futilmente à sensação sem propósito, cultivada num epicurismo subutilizado, como convém aos nossos nervos cerebrais." (PESSOA, 1999, p.45).

Enquanto Bernardo Soares apresenta como resposta para os dilemas do tempo em que lhe foi dado viver a perspectiva de adotar "a renúncia por modo e a contemplação por destino", Charles Baudelaire "desposa a multidão" das ruas da cidade, buscando nelas a matéria de sua prosa poética, que não deixará de lançar um olhar oblíquo ao cenário democrático que a Revolução Francesa, execrada por Soares, criou:

Um homem assustador entra e se olha no espelho.

"Por que está se olhando no espelho, se somente com desagrado pode se ver?

O homem assustador me responde: "Senhor, de acordo com os imortais princípios de 89, todos os homens são iguais em direitos; tenho o direito de me olhar; com ou sem agrado, isso é com a minha consciência."

Em nome do bom senso, sem dúvida, eu estava com a razão; mas do ponto de vista da lei, ele não estava errado." (BAUDELAIRE, 1995, p. 125).

Se o poeta, para Baudelaire precisa estar em dia com seu tempo, para Pessoa este deve se refugiar das ameaças constantemente oferecidas pela dinâmica da vida moderna à sua sensibilidade. Esta espécie de recuo conservador diante da realidade histórica é, no entanto, apresentada por meio de uma forma inusitadamente contemporânea, fragmentária e desalinhavada, compondo um todo heteróclito de difícil definição. Conforme Leyla PerroneMoisés:

O Livro do desassossego, em suas inúmeras facetas, é uma espécie de mostruário de tudo o que se fez na literatura ocidental desde o romantismo alemão, passando pelo decadentismo do fim do século XIX, até as invenções verbais e sintáticas mais ousadas de nosso século; e não necessariamente nessa ordem cronológica. Da máxima clássica ao poema em prosa, deste ao désoeuvrement da obra fragmentária moderna, tudo cabe na prosa fluida de Bernardo Soares. (MOISÉS,2000, p.149). 
Cabe, de fato, muita coisa na prosa fluída de Bernardo Soares, inclusive certo tom de saudosismo antimoderno, que o afasta da modernidade mais avançada presenciada em seus próprios dias. Compartilhando com Charles Baudelaire este olhar que se dirige ao banal do dia-a-dia, percebido como substância mesma da vida do homem moderno, a prosa poética de Bernardo Soares pode de fato ser reconhecida como moderna. Fernando Pessoa, autor do autor do Livro, chega mesmo a amar seu prosaico trabalho, não se satisfazendo em apenas aceitá-lo na contingência de sua vida:

Tenho ternura, ternura até às lágrimas, pelos meus livros de outros em que escrituro, pelo tinteiro velho de que me sirvo, pelas costas dobrados do Sérgio, que faz guias de remessa um pouco para além de mim. Tenho amor a isto, talvez porque não tenha mais nada que amar - ou talvez, também, porque nada valha o amor de uma alma, e, se temos por sentimento que o dar, tanto vale dá-lo ao pequeno aspecto do meu tinteiro como à grande indiferença das estrelas. (PESSOA, 1999, p.51)

A inusitada declaração de amor aos seres e objetos do escritório da Rua dos Douradores convive proximamente, no entanto, com apreciações completamente distintas dessa que se referiu. No fragmento 36, por exemplo, lê-se:

\begin{abstract}
Não são as paredes reles do meu quarto vulgar, nem as secretárias velhas do escritório alheio, nem a pobreza das ruas intermédias da Baixa usual, tantas vezes por mim percorridas que já me parecem Ter usurpado a fixidez da irreparabilidade, que formam no meu espírito a náusea, que nele é freqüente, da quotidianidade enxovalhante da vida. São as pessoas que habitualmente me cercam, são as almas que, desconhecendo-me, todos os dias me conhecem com o convívio e a fala, que me põem na garganta do espírito o nó salivar do desgosto físico. É a sordidez monótona da sua vida, paralela à exterioridade da minha, é a sua consciência íntima de serem meus semelhantes, que me veste o traje de forçado, me dá a cela de penitenciário, me faz apócrifo e mendigo. (PESSOA, 1999, p.71)
\end{abstract}

A "quotidianidade enxovalhante da vida" vai ser entendida por Baudelaire como a única dimensão em que é dado ao poeta moderno viver. Walter Benjamin, um de seus mais importantes críticos, caracterizou o estilo do autor de As flores do mal como resultante de uma união "entre o estilo literário de Racine ao de um jornalista do Segundo Império" (BENJAMIN, 1989, p. 97). Jornalista porque impregnado da substância do presente, mergulhado no presente como cenário inevitável:

O poeta goza desse incomparável privilégio de poder, quando lhe agrada, ser ele mesmo e um outro. Como essas almas errantes que buscam um corpo, ele entra, se quiser, na personagem de alguém.

O passeante solitário e pensativo extrai uma singular embriaguez dessa universal comunhão. Quem facilmente desposa a multidão conhece prazeres febris, de que eternamente se privarão o egoísta, fechado como um cofre, e o preguiçoso, internado como um molusco. Já ele chama a si todas as profissões, todas as alegrias e todas as misérias que lhe apresente a circunstância.(BAUDELAIRE, 1995, p.41). 
Traço central da lírica moderna, a poesia de Baudelaire parece prescindir da exploração do eu pessoal do artista, passando a constituir um jogo polifônico de vozes, como se a subjetividade pura não mais pudesse representar a sensibilidade de uma época marcada pela presença das grandes massas urbanas no cenários das ruas modernas.

Convivem, portanto, no interior do Livro do desassossego colocações muito disparatadas entre si, por vezes identificadas com o sentimento eminentemente moderno da aceitação da fugacidade da vida e da valorização do instante passageiro e em outras circunstâncias, o sentimento é exatamente outro, em tudo oposto àquele anterior, revelando uma recusa e uma rejeição a tudo que identifica a vida moderna.

Nos Poemas em prosa, pelo contrário, uma sensibilidade eminentemente moderna se expressa por meio de uma forma fragmentária, identificada com a descontinuidade da vida moderna. Ali encontra-se também, em "Perda de auréola", um de seus momentos mais comentados, a representação de do papel do artista no cenário que se descortinava aos olhos do poeta. Diante das novas exigências da vida e do consumo modernos, cabia ao poeta despojar-se de sua "aura", aceitando os benefícios mundanos da nova condição: "Agora posso passear incógnito, [...] agora estou igualzinho a você, como pode ver! [...] Me sinto bem." (BAUDELAIRE, 1995, p. 137).

Se na mélange insólita do Livro do desassossego há a representação da inconstância da vida e da sensibilidade modernas, "Tudo me interessa e nada me prende" (fragmento 10, p.53), parece também haver a rejeição de muitas das características da modernidade. Homem de seu tempo e homem preso ao passado, Bernardo Soares encarna em si todas as contradições do presente. Nos poemas em prosa, por sua vez, as vicissitudes da vida e da arte moderna encontram-se representadas com radicalidade, por meio de uma forma que ainda hoje instiga aqueles que se interessam pela ousadia de uma arte que não recusa embriagar-se de presente.

\section{Referências}

BAUDELAIRE, Charles. O pintor da vida moderna. Lisboa: Veja, 1993. CRUZ, Teresa. "Posfácio":p.63-102.

BAUDELAIRE, Charles. O Spleen de Paris. Pequenos poemas em prosa. Rio de Janeiro: Imago, 1995.

BENJAMIN, Walter. Charles Baudelaire: um lírico no auge do capitalismo. Obras escolhidas volume III. São Paulo: Brasiliense, 1989. 
BERMAN, Marshall. Tudo que é sólido se desmancha no ar: a aventura da modernidade. São Paulo: Cia das Letras, 1986.

BRADBURY, Malcolm, MCFARLANE, James. Guia geral do modernismo. 2.ed. São Paulo: Cia das Letras, 1999.

FRIEDRICH, Hugo. Estrutura da lírica moderna. (da metade do século XIX a medos do século XX) 2.ed. São Paulo, 1991.

MOISÉS, Leyla Perrone. "Pessoa de todos (os)nós". In: Inútil poesia. São Paulo: Cia das Letras, 2000, p.145-50.

PESSOA, Fernando. Livro do desassossego. 2.ed. São Paulo: Cia das Letras, 1999. 